\title{
Successful surgical and medical treatment of a severe, acute epidural bleed in a young dog due to steroid responsive meningitis-arteritis
}

\author{
Jessica Zilli* ${ }^{*}$, Agnieszka Olszewska, Daniela Farke and Martin Jürgen Schmidt
}

\begin{abstract}
Background: Steroid responsive meningitis-arteritis (SRMA) is an immune-mediated disease of the leptomeninges and its associated blood vessels, typically responsive to corticosteroids. Clinically relevant haemorrhage is a rare finding in such patients and for this reason surgical decompression of the spinal cord is normally not considered. The diagnosis of SRMA is supported by serum C-reactive protein (CRP) increase, cerebrospinal fluid (CSF) examination, including cytology (polymorphonuclear pleocytosis in the acute form), nucleated cell-, red blood cell- and protein count, as well as by evaluating CSF and serum IgA concentrations. D-dimer concentrations in serum and CSF should be elevated as well and therefore can be also evaluated as a further diagnostic tool.
\end{abstract}

Case presentation: A 1.5-year-old mixed breed dog was presented with pyrexia, cervical pain and acute tetraparesis. Magnetic resonance imaging revealed an extradural mass lesion at the level of the sixth cervical vertebra, consistent with a subacute epidural haemorrhage, causing severe compression of the spinal cord. Based on the dog's signalment, clinical history and results of the blood and CSF analyses (incl. D-dimer determination), SRMA with secondary epidural haemorrhage was suspected. Decompressive surgery was performed through a right sided partial dorsal laminectomy. Post-surgical immunosuppressive treatment was started with cytarabine and then continued with prednisolone after completion of wound healing.

Conclusions: This is the first report in which medical and surgical treatment were combined in a patient with SRMA and it highlights the possibility of performing a successful surgical intervention despite the need for immunosuppressive therapy. Moreover, while SRMA diagnosis is normally based on CSF analysis and CSF and serum IgA concentrations, D-dimer concentrations in serum and CSF were also useful in this patient.

Keywords: Canine, Cervical pain, Cytosine arabinoside, Decompression, Inflammatory disease, Immune-mediated, Tetraparesis

\section{Background}

Steroid responsive meningitis-arteritis (SRMA) is an immune-mediated inflammatory disorder targeting the leptomeninges and its associated vessels [1]. An underlying mechanism is the dysregulation of the immune

*Correspondence: jessica.zilli@vetmed.uni-giessen.de

Small Animal Clinic-Neurosurgery, Neuroradiology and Clinical Neurology, Justus Liebig University-Giessen, Frankfurterstrasse 114, 35392 Giessen, Germany response leading to release of interleukin 8 and a CD11a upregulation, which act both as a chemotactic factor for polymorphonuclear leukocytes [2,3] and a massive upregulation of immunoglobulin A (IgA), due to a Th2mediated immune response [4]. The subsequent leakage of the blood-brain barrier and stimulation of the immune system leads to an invasion of the leptomeninges with neutrophils and to the development of a necrotising arteritis [3]. The aetiopathological mechanism which leads to the arteritis is still not completely understood.

(c) The Author(s) 2021. This article is licensed under a Creative Commons Attribution 4.0 International License, which permits use, sharing, adaptation, distribution and reproduction in any medium or format, as long as you give appropriate credit to the original author(s) and the source, provide a link to the Creative Commons licence, and indicate if changes were made. The images or other third party material in this article are included in the article's Creative Commons licence, unless indicated otherwise in a credit line to the material. If material is not included in the article's Creative Commons licence and your intended use is not permitted by statutory regulation or exceeds the permitted use, you will need to obtain permission directly from the copyright holder. To view a copy of this licence, visit http://creativeco mmons.org/licenses/by/4.0/. The Creative Commons Public Domain Dedication waiver (http://creativecommons.org/publicdomain/ zero/1.0/) applies to the data made available in this article, unless otherwise stated in a credit line to the data. 
In fact, although it was hypothesised that the deposition of immune complexes in these vessels could play a role in generating vascular damage, no immune complex deposits were found in acute lesions and also the deposition of immunoglobulins was rarely observed and only in chronic cases [5].

Young, medium to large breed dogs are commonly affected. The age of onset is typically between six and 18 months with a range from 4 months to 9 years [6]. Bernese Mountain dogs, Beagles, Boxers, Nova Scotia Duck Tolling Retrievers and Weimaraners are predisposed [3]. Clinical signs include lethargy, pyrexia, severe cervical hyperesthesia and pain. A stiff gait and reluctance to walk are also common. In the chronic stage of the disease, neurological signs compatible with cervical or multifocal myelopathy can be evident [7]. The diagnosis of SRMA is supported by serum C-reactive protein (CRP) increase, cerebrospinal fluid (CSF) examination, including cytology (polymorphonuclear pleocytosis in the acute form), nucleated cell-, red blood cell- and protein count, as well as by evaluating CSF and serum IgA concentrations. Treatment consists of immunosuppressive doses of prednisolone or prednisone and is usually followed by a rapid improvement. For the acute as well as for the chronic or refractory cases, a combination of azathioprine and glucocorticoids has also proven effective $[8,9]$. For relapses, the efficacy of a combination of prednisolone and cytosine arabinoside has been demonstrated as well [10]. In one study, mycophenolate mofetil has been also used for the treatment of dogs with relapses [6]. The prognosis in dogs with acute disease is good if they are adequately treated; however, relapses can occur [3]. Although structural damage to the small calibre arteries can be seen in the histopathological examination of the brain and spinal cord, clinically overt haemorrhage is rarely seen in the acute form of the disease $[6,7$, 11]. Here, we report on medical and surgical treatment of spinal haemorrhage that occurred in association with SRMA.

\section{Case presentation}

A 1.5-year-old neutered male, mix-breed dog (body weight: $20 \mathrm{~kg}$ ) was referred to the Small Animal Hospital of the Justus-Liebig-University, Giessen due to pyrexia and a 5-day history of progressive tetraparesis, cervical hyperaesthesia, inappetence and lethargy. Treatment with metamizole, meloxicam and unrecorded antibiotics prescribed from the referring veterinarian caused only a mild improvement of clinical signs. On the initial clinical examination, the dog showed an elevated body temperature of $39.7{ }^{\circ} \mathrm{C}$. Neurological examination revealed non-ambulatory tetraparesis with absent proprioceptive positioning and hopping in all four limbs. Spinal reflexes were increased in the hindlimbs, whereas the flexor reflex was decreased in the left front limb. Additionally, the dog showed severe cervical pain especially by latero- and dorsiflexion of the neck. Furthermore, diffuse pain on palpation along the whole spine was observed. Neuroanatomical localisation was multifocal with spinal segments C6-Th2 mainly being suspected. A complete blood count and blood chemistry profile were performed and showed a marked leucocytosis, neutrophilia and monocytosis, moderate hyperglobulinemia and marked increase of CRP (148 mg/L; reference: < $14.9 \mathrm{mg} / \mathrm{L}$ ). Radiographs of the thorax and spine as well as abdominal ultrasound were unremarkable.

Magnetic resonance imaging (MRI) of the cervical spine was performed under general anaesthesia using a 3.0-T scanner (MAGNETOM Verio, Siemens Healthcare) and a commercially available body coil. Multiplanar T2-weighted (T2W), T1-weighted pre- and post-contrast (T1W), fluid attenuated inversion recovery (FLAIR), Gradient Echo, Short Inversion Time Inversion Recovery (STIR) and 3D Constructive Interference in Steady State (CISS) sequences were acquired. The MRI study showed an ovoid extramedullary and extradural, right sided, well demarcated mass lesion at the level of C6 causing a severe compression of the spinal cord, which was displaced to the left. The lesion had a heterogeneous hypointense signal on T2W and T1W images, slightly hyperintense on STIR images and showed a mild contrast enhancement. Moreover, the lesion showed a mild, heterogeneous susceptibility artefact. A similar lesion without compression of the spinal cord was observed at the level of $\mathrm{C} 2$ on the CISS images. At this level, a heterogeneous subarachnoidal/subdural material encircled the spinal cord. This material was moderately hyperintense in T2, STIR and iso- to hypointense in T1. Very mild contrast enhancement was visible and a susceptibility artifact was noted as well. Based on the MRI findings, the presumptive diagnosis of subacute, multifocal, epidural haemorrhages was made (Fig. 1). The differential diagnosis included primary and secondary coagulation disorders, infectious and inflammatory disease. CSF was taken from the cisterna magna directly after the MRI examination. It was xanthochromic with a severe pyogranulomatous pleocytosis, elevated erythrocyte count (119.196 cells/ $\mu \mathrm{L}$; reference: $<1500$ cells $/ \mu \mathrm{L}$ ) and protein concentration $(2470.7 \mathrm{mg} / \mathrm{L}$; reference: $<300 \mathrm{~g} / \mathrm{L})$. A leucocyte count was not possible due to massive erythrocyte contamination within the sample. Additionally, the D-dimer concentration was determined by immunoturbidimetry in the CSF and serum samples and was elevated in both $(3.68 \mu \mathrm{g} / \mathrm{mL}$ and $3.43 \mu \mathrm{g} / \mathrm{mL}$, respectively; serum reference: $<0.67 \mu \mathrm{g} / \mathrm{mL}$ ). CSF D-dimer from two control dogs presented on the same day were also measured $(0.16 \mu \mathrm{g} /$ 


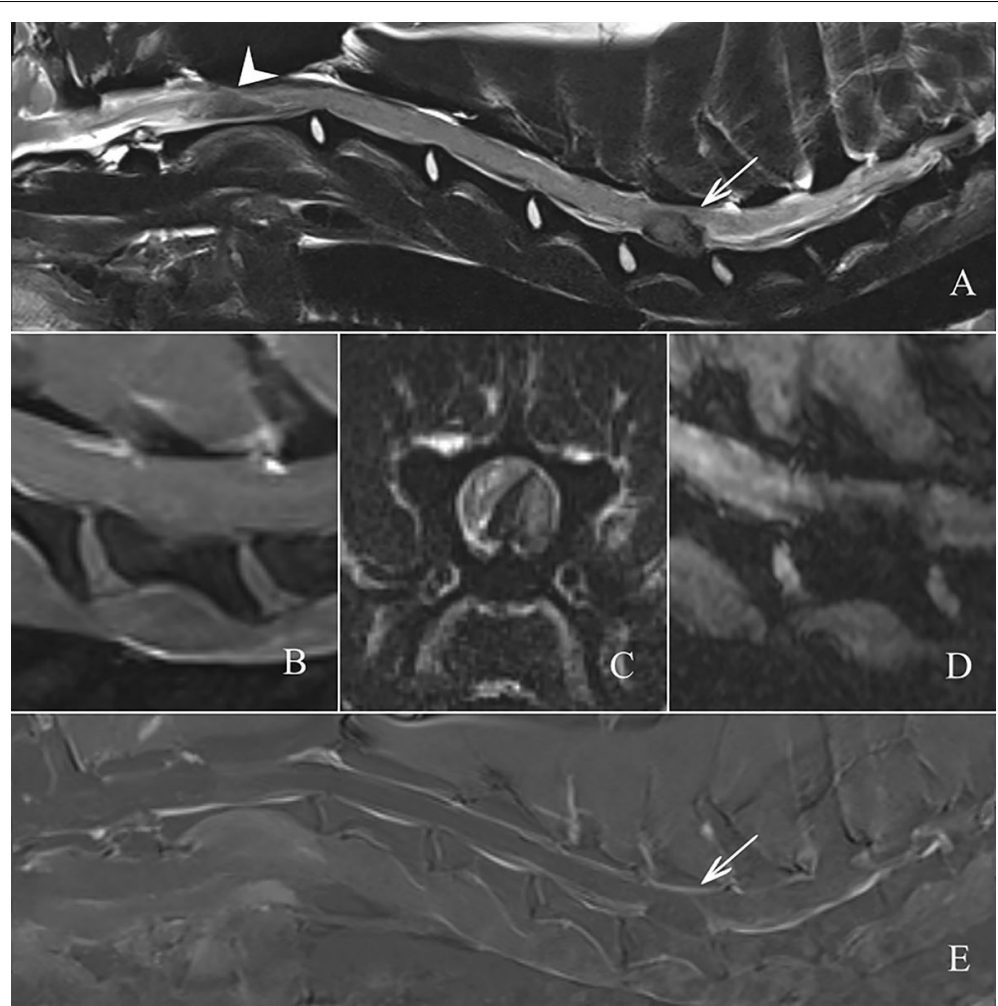

Fig. 1 Magnetic resonance imaging of the cervical spine. Extramedullary, extradural, well defined, mildly heterogeneous, oval mass lesion at the level of C6 (arrows). The lesion is hypointense in T2 sagittal (A) and transverse (C), T1 sagittal (B) and mildly hyperintense in STIR. This mass is ventral and right sided, occupying ca. 70\% of the vertebral canal with moderate to severe mass effect on the spinal cord that appears displaced towards the left lateral side. The mass shows a mild heterogeneous susceptibility artefact in the sagittal T2 FFE sequence (D) and minimal contrast enhancement in the T1 subtraction sequence $(\mathbf{E})$. At the level of C2 the spinal cord appears increased in volume. In the CISS sequence there is a circumferential heterogeneous subarachnoideal/subdural material encircling the spinal cord with mixed hyper-hypointense areas. This material is moderate hyperintense in T2 (arrowhead, A), STIR and iso- to hypointense in T1. Very mild contrast enhancement is visible (E). Susceptibility artifact is noted

$\mathrm{mL}$ and $0.09 \mu \mathrm{g} / \mathrm{mL}$ ). Given the evidence of epidural haemorrhage, coagulation markers (prothrombin time, partial thromboplastin time, mucosal bleeding time and thrombelastogram) were tested and revealed no abnormalities. The test for Angiostrongylus vasorum antigens (Angio Detect) was negative. Based on these findings and in the absence of primary coagulopathies, the presumptive diagnosis of SRMA with secondary, multifocal, epidural haemorrhage was made. In order to confirm the diagnosis, the IgA concentration from serum $(137.6 \mu \mathrm{g} /$ $\mathrm{mL})$ and CSF $(5.7 \mu \mathrm{g} / \mathrm{mL})$ was tested; both were elevated (reference ranges: serum 10.9-100.1 $\mu \mathrm{g} / \mathrm{mL}$; CSF $0.0-$ $0.2 \mu \mathrm{g} / \mathrm{mL}$ ). The IgA concentrations were measured by using an enzyme-linked immunosorbent assay (ELISA).

Due to the severe spinal cord compression, decompressive surgery was performed. The dog received premedication with diazepam $(0.5 \mathrm{mg} / \mathrm{kg})$ and atropine $(0.015 \mathrm{mg} / \mathrm{kg})$. Propofol $(3 \mathrm{mg} / \mathrm{kg})$ was used to induce anaesthesia. General anaesthesia was maintained with isoflurane and fentanyl $(40 \mu \mathrm{g} / \mathrm{kg} / \mathrm{h})$. Further medications included ampicillin $(50 \mathrm{mg} / \mathrm{kg}$ ), amoxicillin-clavulanic acid $(10 \mathrm{mg} / \mathrm{kg})$ and metamizole $(50 \mathrm{mg} / \mathrm{kg})$. A right sided partial dorsal laminectomy at the level of C6 was performed and the epidural haemorrhage was removed (Fig. 2). In order to reduce the likelihood of further bleeding during the procedure, the dog was administered tranexamic acid $(10 \mathrm{mg} / \mathrm{kg}, \mathrm{IV})$.

Post-surgical treatment included immunosuppression with cytosine arabinoside $\left(60 \mathrm{mg} / \mathrm{m}^{2}, \mathrm{SC}\right.$ q12 h over 48 h), fluid therapy using crystalloid solutions (sterofundin $4 \mathrm{~mL} / \mathrm{kg} / \mathrm{h}$, IV), pain medication (fentanyl CRI at a dosage of $5 \mu \mathrm{g} / \mathrm{kg} / \mathrm{h}, \mathrm{IV}$ ), antibiotics (amoxicillin-clavulanic acid at a dosage of $20 \mathrm{mg} / \mathrm{kg}$, PO q12 h), anti-inflammatory (carprofen at a dosage of $4 \mathrm{mg} / \mathrm{kg}, \mathrm{PO} \mathrm{q} 24 \mathrm{~h}$ ) and gastroprotective agents (omeprazole at a dosage of $1 \mathrm{mg}$ / $\mathrm{kg}$, PO q24 h).

Treatment with tranexamic acid $(12.5 \mathrm{mg} / \mathrm{kg}$, PO q8 h) was continued for 4 days and combined with a constant rate infusion of metoclopramide $(15 \mu \mathrm{g} / \mathrm{kg} / \mathrm{h})$, due to its potential emetic effects. Corticosteroid therapy was 


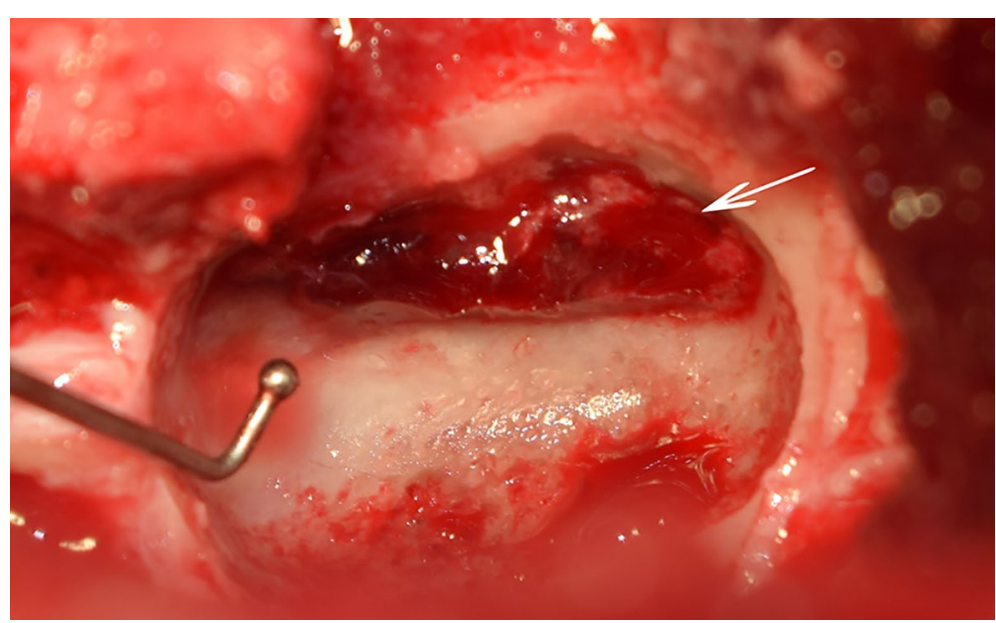

Fig. 2 Surgery. Intraoperative image of the surgical field after right sided, partial dorsal laminectomy over C6. The arrow shows the epidural haemorrhage before removal

not started because of its known side effects on wound healing and coagulation. The dog returned to ambulation 4 days after surgical treatment. Cervical pain also significantly improved, and the dog was discharged from the hospital one week after surgery. Prednisolone treatment was started with a dosage of $0.6 \mathrm{mg} / \mathrm{kg}$ q $24 \mathrm{~h}$ after completion of wound healing (12 days after surgery).

At follow-up 4 weeks later, the dog showed a mild proprioceptive ataxia of all limbs. CSF collection under general anaesthesia was repeated. Cytological examination still showed mild blood contamination, with predominance of red blood cells. Prednisolone therapy was continued. Serum C-reactive protein was within the normal limits $(1.3 \mathrm{mg} / \mathrm{L}$; reference: < $14.9 \mathrm{mg} / \mathrm{L})$. Eight weeks after surgery, the owners reported a further improvement of the dog's gait and locomotion. On neurological examination, a mild hypermetric gait of all limbs remained, probably still related to the involvement of the spino-cerebellar tract at the level of C6. The postural reactions were normal, and the dog showed just a mild reluctance to cervical ventroflexion of the neck. Due to the further improvement, prednisolone was further tapered: $0.46 \mathrm{mg} / \mathrm{kg}$ q24 h over a further 6 weeks followed by $0.3 \mathrm{mg} / \mathrm{kg} \mathrm{q} 24 \mathrm{~h}$ over a further 4 weeks. Prednisolone therapy should have been discontinued 6 weeks later but the dog died shortly before for reasons unrelated to SRMA.

\section{Discussion and conclusions}

This is the first case reporting successful combination of surgical and medical treatment in a dog with SRMA and secondary bleeding. Dogs affected with this immunemediated disorder can develop haemorrhages anywhere in the entire central nervous system; however, these are rarely clinically relevant, as in the case described here [7, 11]. The development of an epidural bleeding was probably due to the associated arteritis, typical of SRMA, and was responsible for a severe compression of the spinal cord at the level of C6. For this reason, the dog needed a surgical decompression. However, since SRMA is primarily a leptomeningitis with the arteritis affecting pia mater and arachnoid mater, an epidural haemorrhage can be considered atypical. Nevertheless, a systemic vasculitis and perivasculitis have been described as well; indeed, this inflammatory process can also involve small to medium-sized arteries in the heart, cranial mediastinum, and cervical spinal meninges (including dura mater) [12], which could account for the presence of an epidural haemorrhage in the dog of our case report.

As aforementioned, the standard treatment protocol for SRMA consists of a long-term immunosuppressive and/or immunomodulatory treatment with prednisolone or prednisone [7]. Nevertheless, steroids are well known for potentially delaying and inhibiting wound healing by interfering with inflammation, fibroblast proliferation, collagen synthesis and degradation, deposition of connective tissue ground substances, angiogenesis, wound contraction and re-epithelization [13]. Moreover, corticosteroids can also interfere with coagulation producing a hypercoagulable state [14], which was undesirable in the dog of the present report who was already receiving tranexamic acid. In order to prevent post-operative healing complications and any other side effects related to the administration of steroids (i.e., gastrointestinal bleedings, interference with coagulation), an alternative therapeutic strategy was developed: the administration 
of prednisolone was postponed, and immunotherapy was started with cytosine arabinoside. This chemotherapeutic agent is a pyrimidine antimetabolite, which prevents cell proliferation by inhibiting DNA synthesis. In veterinary neurology, it is usually employed in the treatment of meningoencephalitis of unknown origin [15]. With the protocol used here, side effects are very infrequent, nevertheless myelosuppression and gastrointestinal toxicity can occur $[16,17]$. Indeed, even if thrombocytopenia has been described in dogs and humans as a consequence of myelosuppression, this occurs only at higher doses than the one used in this report or if cytarabine is used as part of a combination chemotherapy protocol [10, 18-20]. In contrast to corticosteroids, a further influence of cytosine arabinoside on coagulation has not been described so far. This was also confirmed by some human and in vitro studies [21-23]. Moreover, a negative effect on wound healing or rather an antiproliferative effect due to the administration of cytarabine was only demonstrated on ocular tissues in vitro and in vivo (rabbits) [24, 25]. For all these reasons, its use in our patient was considered beneficial and it indeed proved to be an effective therapeutic alternative to corticosteroids in the acute phase of SRMA, which correlates with a previous study [10]. The dog showed a fast improvement of clinical signs and no post-operative complications were observed. During a 4.5 months follow-up-period after surgery, the dog did not show any recurrence of the clinical signs and the owners reported a further improvement of his neurological status at home. Unfortunately, it died shortly before interruption of the prednisolone therapy for unrelated reasons.

An intrathecal fibrinolytic pathway was activated in the CSF of the present dog with SRMA, in agreement with SRMA-dogs in the report by de la Fuente et al. [26]. In these animals, the abnormal high levels of D-dimer can be explained by the presence of vasculitis and sometimes also of subarachnoid bleeding and consequent clot formation [26]. The D-dimer concentration was severely increased not only in the serum but also in the CSF of the dog, considering the ranges obtained for CSF D-dimer in one study that evaluated their concentrations in dogs with various diseases of the central nervous system [26].

Peri- and post-operatively, tranexamic acid, an antifibrinolytic agent $[27,28]$, was administered in order to reduce the risk of further bleeding. In human medicine, this haemostatic agent, which prevents hyperfibrinolysis, has already been demonstrated as an effective and safe treatment option if used topically or intravenously during spinal surgeries, predominantly in cases with significant anticipated surgical site blood loss [29]. For this reason, its use should also be considered in animals with a high risk of bleeding, e.g. if they undergo spinal surgery.
Coagulation and inflammation are interrelated processes: inflammation can activate coagulation and vice versa, coagulation can affect the inflammatory process [30-35]. Fibrinolysis is the enzymatic process responsible for the removal of intravascular fibrin clots. This process avoids unnecessary intravascular accumulation of fibrin and is an important component of normal haemostasis. The products of fibrin degradation are the D-dimers, which are used as important predictive and prognostic factors in many vascular diseases, like disseminated intravascular coagulation, pulmonary embolism and thrombosis [36]. Indeed, this biomarker could also be employed as a further diagnostic tool when SRMA is suspected, especially while awaiting IgA quantification results in those cases in which the presence of blood contamination in the CSF makes the diagnosis challenging. In fact, haemorrhage could hinder the detection of the typical polymorphonuclear pleocytosis. The parameter could be also used for monitoring the disease. A similar importance can be attributed to the evaluation of CRP, which is normally elevated in the serum of dogs with SRMA in the acute phase of the disease and could also be assessed in the CSF. Indeed, whereas IgA measuring takes many days, CRP and D-dimer quantification takes no longer than a few hours, since it is often available as an in-house test. Further studies are nevertheless required to establish $\mathrm{D}$-dimer concentration ranges in the CSF of normal dogs and to evaluate its concentrations in dogs with acute SRMA in comparison to other central neurological disorders (especially neoplastic and other inflammatory conditions). In this regard, a study already showed that dogs with central nervous system neoplasia or other inflammatory diseases also have increased D-dimer concentrations but still not as high as in animals affected by SRMA [26]. Since reference ranges for CSF D-dimer has not been defined yet, we compared the values obtained in the dog of this report to the ones of the above-mentioned study [26] and considered ours to be increased, even in comparison to the ones measured from the other two dogs presented on the same day in the hospital. These were a 6-year-old female, Cavalier King Charles Spaniel with focal epileptic seizures 4 years after cystoperitoneal shunt implantation due to a supracollicular fluid accumulation $(0.16 \mu \mathrm{g} / \mathrm{mL})$ and one 13-year-old neutered female, German Shepard dog with suspected degenerative myelopathy $(0.09 \mu \mathrm{g} / \mathrm{mL})$. However, the significance of this biomarker in dogs with SRMA and secondary haemorrhage in comparison to those affected animals who do not show any evidence of bleeding still has to be evaluated.

In conclusion, in this report a rare case of clinically relevant epidural bleeding secondary to SRMA in a dog was described. In order to support SRMA diagnosis 
while awaiting IgA confirmation and in presence of blood contamination in the CSF, the evaluation of the D-dimer concentration was used as further diagnostic confirmation. Moreover, the therapeutic protocol used in this case report, which combined surgical decompression and immunosuppressive therapy with cytosine arabinoside, was successful and the dog did not develop any complications. Indeed, cytosine arabinoside administration after surgery proved to be an effective alternative to steroidal immunosuppressive and immunomodulatory drugs in specific cases in the acute phase of the disease.

\section{Abbreviations \\ CISS: 3D Constructive Interference in Steady State; CSF: Cerebrospinal fluid; CRP: C-reactive protein; ELISA: Enzyme-linked immunosorbent assay; FLAIR: Fluid attenuated inversion recovery; MRI: Magnetic resonance imaging; SRMA: Steroid responsive meningitis-arteritis; STIR: Short Inversion Time Inversion Recovery; T1W: T1-weighted; T2W: T2-weighted.}

\section{Acknowledgements}

Not applicable.

\section{Prior publication}

Data included in this article have previously been published in the Proceedings of the 32nd ESVN-ECVN Symposium, Wroclaw, Poland, September 13-14, 2019.

\section{Authors' contributions}

JZ and AO drafted the manuscript. JZ, DF and MS were all involved in the clinical procedures concerning the patient. MS supervised the case and furnished funding and materials. All authors read and approved the final manuscript.

\section{Funding}

Open Access funding enabled and organized by Projekt DEAL.

This study was funded by the Small Animal Clinic-Surgery of the Justus-Liebig-University-Giessen.

\section{Availability of data and materials}

The datasets used and/or analysed during the current study are available from the corresponding author on reasonable request.

\section{Declarations}

\section{Ethics approval and consent to participate}

This study did not require official or institutional ethical approval. The dog was handled according to good veterinary practice and German veterinary regulations.

\section{Consent for publication}

Written informed consent was obtained from the owner of the animal.

\section{Competing interests}

The authors declare that they have no competing interests.

Received: 29 January 2021 Accepted: 5 July 2021

Published online: 10 July 2021

\section{References}

1. De Lahunta A, Glass E, Kent M. Small animal spinal cord disease. In: De Lahunta A, Glass E, Kent M. Veterinary neuroanatomy and clinical neurology. 4th ed. Canada: Saunders, Elsevier Science; 2015. p. 257-303.
2. Burgener I, Ham L, Jaggy A, Vandevelde M, Tipold A. Chemotactic activity and IL-8 levels in the cerebrospinal fluid in canine steroid responsive meningitis-arteritis. J Neuroimmunol. 1998;89:182-90.

3. Tipold A, Schatzberg J. An update on steroid responsive meningitisarteritis. J Small Anim Pract. 2010;51:150-4.

4. Schwartz M, Moore PF, Tipold A. Disproportionally strong increase of B cells in inflammatory cerebrospinal fluid of dogs with steroidresponsive meningitis-arteritis. Veterinary Immunol Immunopathol. 2008;125:274-83.

5. Tipold A, Vandevelde M, Zurbriggen A. Neuroimmunological studies in steroid-responsive meningitis-arteritis in dogs. Res Vet Sci. 1995;58:103-8.

6. Cizinauskas S, Jaggy A, Tipold A. Long-term treatment of dogs with steroid-responsive meningitis-arteritis: clinical, laboratory and therapeutic results. J Small Anim Pract. 2000:41:295-301.

7. Dewey CW, Da Costa RC. Myelopathies: disorders of the spinal cord. In: Dewey CW, Da Costa RC, editors. Practical guide to canine and feline neurology. Chichester, West Sussex: Wiley Blackwell; 2016. p. 379-81.

8. Giraud L, Girod M, Cauzinille L. Combination of prednisolone and azathioprine for steroid-responsive meningitis-arteritis treatment in dogs. JAAHA. 2020. https://doi.org/10.5326/JAAHA-MS-7019.

9. Tipold A. Steroid-responsive meningitis-arteritis in dogs. In: Bonagura JD, editor. Kirk's current veterinary therapy XIII: small animal practice. Philadelphia: Saunders; 2000. p. 978-81.

10. Günther C, Steffen F, Alder DS, Beatrice L, Geigy C, Beckmann K. Evaluating the use of cytosine arabinoside for treatment for recurrent canine steroid-responsive meningitis-arteritis. Vet Rec. 2020;187: e7. https://doi. org/10.1136/vr.105683.

11. Vandevelde M, Higgins R, Oevermann A. Inflammatory diseases. In: Vandevelde M, Higgins R, Oevermann A, editors. Veterinary neuropathology: essentials of theory and practice. 1st ed. New York: Wiley; 2012. p. 48-80.

12. Snyder PW, Kazacos EA, Scott-Moncrieff JC, HogenEsch H, Carlton WW, Glickman LT, Felsburg PJ. Pathologic features of naturally occurring juvenile polyarteritis in Beagle dogs. Vet Pathol. 1995;32:337-45.

13. Anstead GM. Steroids, retinoids, and wound healing. Adv Wound Care. 1998;11:277-85.

14. Ungemach FR. Kortikosteroide. In: Löscher W, Ungemach FR, Kroker R, editors. Pharmakotherapie bei Haus- und Nutztieren. 7th ed. Stuttgart, Germany: MVS; 2006. p. 384-403.

15. Talarico LR, Schatzberg SJ. Idiopathic granulomatous and necrotising inflammatory disorders of the canine central nervous system: a review and future perspectives. J Small Anim Pract. 2010;51:138-49.

16. Dewey CW. Encephalopathies: disorders of the brain. In: Dewey CW, Da Costa RC, editors. Practical guide to canine and feline neurology. Chichester: Wiley Blackwell; 2016. p. 141-236.

17. Hirschberger J. Medikamente, Dosierungen, Behandlungsprotokolle. In: Kleintieronkologie Kessler M, editor. Diagnose und Therapie von Tumorerkrankungen bei Hund und Katze. 3rd ed. Stuttgart: MVS; 2013. p. 100-14.

18. Alvarez FJ, Kisseberth WC, Gallant SL, Couto CG, Alvarez FJ, William C, et al. Dexamethasone, melphalan, actinomycin d, cytosine arabinoside (DMAC) protocol for dogs with relapsed lymphoma. J Vet Intern Med. 2006;20:1178-83.

19. Guillen A, Finotello R, Wynne P, Harper A, Killick D, Amores-Futser I, Blackwood L. Toxicity of cytarabine constant rate infusion in dogs with high-grade non-Hodgkin lymphoma with bone marrow or central nervous system involvement. Aust Vet J. 2020;98:69-78.

20. Ruslander D, Moore AS, Gliatto JM, L'Heureux D, Cotter SM. Cytosine arabinoside as a single agent for the induction of remission in canine lymphoma. J Vet Intern Med. 1994;8:299-301.

21. Gagliano RG, Terrebonne AM, Alperin JB, Costanzi JJ. The effect of cytosine arabinoside on platelet aggregation. Cancer. 1976;38:2247-9.

22. Komp DM, Lyles RL Jr, Boyd TH 3rd, Stoner GE, Cox BJ. The effect of cancer chemotherapeutic agents on fibrin formation and stabilization in vitro. Pediatr Res. 1974;8:75-81.

23. Marra R, Pagano L, De Stefano V, Leone G, Bizzi B. Antithrombin III during high-dose cytosine arabinoside therapy with or without asparaginase. Acta Haematol. 1986;75:96-9.

24. Hajek AS, Parrish RK II, Mallick KS, Gressel M. In vitro inhibition of ocular cell proliferation with Ara-C: blockage of the antiproliferative effect with 2'-Deoxycytidine. Invest Ophthalomol Vis Sci. 1986;27:1010-2.

25. Lass JH, Langston RH, Foster CS, Pavan-Langston D. Antiviral medications and corneal wound healing. Antiviral Res. 1984:4:143-57. 
26. de la Fuente C, Monreal L, Ceron J, Pastor J, Viu J, Anor S. Fibrinolytic activity in cerebrospinal fluid of dogs with different neurological disorders. J Vet Intern Med. 2012;26:1365-73.

27. Muri B, Schmierer P, Schwarz A, Sigrist N. Hyperfibrinolysis diagnosed with rotational thromboelastometry and treated with tranexamic acid in a dog with acute traumatic coagulopathy. Schweiz Arch Tierheilkd. 2018;160:227-33.

28. Osekavage KE, Brainard BM, Lane SL, Almoslem M, Arnold RD, Koenig A. Pharmacokinetics of tranexamic acid in healthy dogs and assessment of its antifibrinolytic properties in canine blood. Am J Vet Res. 2018;79:1057-63.

29. Winter SF, Santaguida C, Wong J, Fehlings MG. Systemic and topical use of tranexamic acid in spinal surgery: a systematic review. Global Spine J. 2015;6:284-95.

30. Esmon CT. The impact of the inflammatory response on coagulation. Thromb Res. 2004;114:321-7.

31. Esmon CT. The interactions between inflammation and coagulation. $\mathrm{Br} J$ Haematol. 2005;131:417-30
32. Esmon CT Crosstalk between inflammation and thrombosis. Maturitas. 2008;61:122-31.

33. Levi M, van der Poll T. Two-way interactions between inflammation and coagulation. Trends Cardiovasc Med. 2005;15:254-9.

34. Levi M, van der Poll T. Inflammation and coagulation. Crit Care Med. 2010;38:S26-34.

35. Strukova S. Blood coagulation-dependent inflammation coagulationdependent inflammation and inflammation-dependent thrombosis. Front Biosci. 2006;11:59-80.

36. Chapin JC, Hajjar KA. Fibrinolysis and the control of blood coagulation. Blood Rev. 2015;29:17-24

\section{Publisher's Note}

Springer Nature remains neutral with regard to jurisdictional claims in published maps and institutional affiliations.
Ready to submit your research? Choose BMC and benefit from:

- fast, convenient online submission

- thorough peer review by experienced researchers in your field

- rapid publication on acceptance

- support for research data, including large and complex data types

- gold Open Access which fosters wider collaboration and increased citations

- maximum visibility for your research: over $100 \mathrm{M}$ website views per year

At BMC, research is always in progress.

Learn more biomedcentral.com/submissions 